\title{
Cost-effectiveness of Practice Team-Supported Exposure Training for Panic Disorder and Agoraphobia in Primary Care: a Cluster-Randomized Trial
}

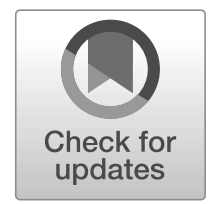

\author{
Christian Brettschneider, $P h D^{7}$, Jochen Gensichen, $M D, M P H^{2,3}$, Thomas S Hiller, MSc ${ }^{3}$, \\ Jörg Breitbart, $M D^{3}$, Ulrike Schumacher, $P h D^{4}$, Karoline Lukaschek, $P h D^{2}$, \\ Tobias Teismann, $P h D^{5}$, Jürgen Margraf, $P h D^{5}$, and Hans-Helmut König, $M D, M P H^{7}$
}

\begin{abstract}
'Department of Health Economics and Health Services Research, Hamburg Center for Health Economics, University Medical Center HamburgEppendorf, Hamburg, Germany; ${ }^{2}$ Institute of General Practice and Family Medicine, University Hospital of Ludwig-Maximilians-University Munich, Munich, Germany; ${ }^{3}$ Institute of General Practice and Family Medicine, Jena University Hospital, Jena, Germany; ${ }^{4}$ Centre for Clinical Studies, Jena University Hospital, Jena, Germany; ${ }^{5}$ Mental Health Research and Treatment Center, Ruhr-Universität Bochum, Bochum, Germany.
\end{abstract}

BACKGROUND: Primary care is the main treatment setting for panic disorder and should be supplemented by collaborative care programs. However, shortage of mental health professionals prevents collaborative care programs from being effectively implemented. The PARADISE study showed the efficacy of a self-managed, cognitivebehavioural therapy (CBT)-oriented exposure training for patients with panic disorder with or without agoraphobia in primary care delivered by the family practice team. OBJECTIVE: To assess the cost-effectiveness of the PARADISE intervention.

DESIGN: Cost-effectiveness analysis from the societal perspective based on data from a cluster-randomized controlled trial over a time horizon of 12 months.

PARTICIPANTS: Four hundred nineteen adult panic disorder patients with or without agoraphobia.

INTERVENTIONS: A self-managed, CBT-oriented exposure training for patients with panic disorder with or without agoraphobia in primary care delivered by the primary care practice team in comparison to routine care. MAIN MEASURES: Total costs from the societal perspective. Direct costs and disease-specific costs. Quality-adjusted life years based on the EQ-5D-3L. Incremental cost-effectiveness ratios and cost-effectiveness acceptability curves.

KEY RESULTS: Patients in the intervention group caused lower costs (mean, $€ 1017 ; 95 \%$ confidence interval [$€ 3306$; $€ 1272]$; $p=0.38$ ) and gained on average more QALY (mean, 0.034 BALY (95\% confidence interval [0.005; 0.062]; $p=0.02$ ). Therefore, the intervention dominated the control treatment. The probability of costeffectiveness of the intervention at a willingness-to-pay margin of $€ 50,000$ per QALY was $96 \%$. Results from supplementary analyses considering direct or disease-

$\overline{\text { Results from this study have been presented at the 9th Conference of the }}$ German Health Economics Association (9/10 March 2017, Basel, CH) and the 12th World Congress in Health Economics (7-11 July 2017, Boston, MA, USA).

Electronic supplementary material The online version of this article (https://doi.org/10.1007/s11606-020-05658-9) contains supplementary material, which is available to authorized users.

Received February 14, 2019

Revised July 9, 2019

Accepted December 23, 2019

Published online January 21, 2020 specific costs instead of total costs showed comparable results.

CONCLUSION: The PARADISE intervention is cost effective. This conclusion is valid for total costs, generic health care (direct) costs, disease-specific health care costs.

TRIAL REGISTRATION: German Clinical Trials Register: DRKS00004386

Current Controlled Trials: ISRCTN64669297

KEY WORDS: self-management; cost-effectiveness; mental health; primary care.

J Gen Intern Med 35(4):1120-6 DOI: $10.1007 / \mathrm{s} 11606-020-05658-9$

(C) The Author(s) 2020

\section{INTRODUCTION}

Panic disorder is defined by recurrent unexpected panic attacks and worries about future attacks and/or the avoidance of specific situations. ${ }^{1}$ Panic attacks are characterized by an abrupt surge of fear in combination with symptoms like sweating, pounding heart or shortness of breath. ${ }^{1}$ Patients with agoraphobia demonstrate marked fear of specific situations like using public transport, visiting marketplaces, theatres or shops or being in a crowd. As a consequence, patients avoid these situations. ${ }^{1}$ Panic disorder and agoraphobia often cooccur $(30-60 \%){ }^{2}$

The 12-month prevalence of panic disorder in Germany is $2 \%$ (95\% confidence interval $1.6-2.5 \%)$. ${ }^{3}$ Women are more frequently affected than men (women $2.8 \%$ [2.2-3.6\%]; men $1.2 \%[0.8-1.8 \%])^{3}$

Studies have shown that panic disorder is associated with a loss of physical and mental quality of $\operatorname{life}^{4,5}$ and a high economic burden. ${ }^{6}$ Furthermore, evidence suggests that a misinterpretation of bodily sensations and health anxiety could increase health care utilization. ${ }^{7,8}$

Primary care is the main treatment setting for patients with anxiety disorders. ${ }^{2,}$ 9, 10 Collaborative care programmes are widely employed in their treatment. ${ }^{11}$ However, due to a 
shortage of mental health professionals and consequently long waiting times for an appointment, ${ }^{12}$ collaborative care programmes incorporating mental health professionals are difficult to implement.

The aim of the "Patient Activation foR Anxiety DISordErs" (PARADISE) study was to implement a self-managed, cognitive behavioural therapy (CBT)-oriented exposure training for patients with panic disorder with or without agoraphobia in primary care delivered by the practice team. The effectiveness of the PARADISE intervention has already been demonstrated. ${ }^{13}$

In this article, we present evidence on the cost-effectiveness of the PARADISE intervention in comparison to usual primary care.

\section{METHODS}

\section{Sample}

The PARADISE study was a cluster-randomized controlled trial comparing a practice team-supported exposure training for panic disorder and agoraphobia in primary care to usual care. Primary care practices registered with the regional Association of Statutory Health Insurance Physicians (Thuringia, Germany) were invited to participate. Inclusion criteria for patients were age 18 years or older; a diagnosis of panic disorder with (ICD-10: F40.01) or without agoraphobia (F41.0); a score of 8 or higher on the Overall Anxiety Severity and Impairment Scale (OASIS) ${ }^{14}$ and a score of 2 or higher on the Patient Health Questionnaire (PHQ) panic module. ${ }^{15}{ }^{16}$ Exclusion criteria were acute suicidal ideation, psychotic or substance-related disorders, severe somatic diseases, pregnancy or current anxiety-specific psychotherapy.

Primary care practices were randomized by location (urban/ rural) in a 1:1 ratio. For further information, please see Gensichen J et al. ${ }^{13}$

\section{Intervention}

All practice teams were instructed in diagnostics and treatment standards of panic disorder in a 2-h session. Practice teams consisted of primary care physicians (PCP) and examined medical assistants (MA), employees with a specific vocational qualification. ${ }^{17} \mathrm{PCP}$ in both groups were free to initiate any medical treatment or refer the patient to other health care professionals (routine care).

In the intervention group (IG), PCP executed the PARADISE programme consisting of four structured appointments over a period of 23 weeks. The first three appointments comprised three major interventions of cognitive-behavioural therapy (psychoeducation; interoceptive exposure exercises, and situational exposure exercises). The fourth appointment provided time to reflect the patient's experiences. In addition, patients were requested to perform practice exposure exercises at least two times a week at home. As support, patients received a workbook. Medical assistants (MA) performed the clinical monitoring of the process by ten telephone contacts. In these contacts, the MA assessed current anxiety severity and adherence to exercises.

\section{ASSESSMENT OF COSTS AND EFFECTS Data Collection}

Data were collected at baseline (T0), after 6 months (T1), and after 12 months (T2) by a self-reported questionnaire. In addition to resource utilization and preference-based healthrelated quality of life (EQ-5D-3L ${ }^{18}$ ), we collected data on sociodemographics, severity of anxiety (Beck Anxiety Inventory $[\mathrm{BAI}]^{19,20}$ ) and comorbidities.

\section{Costs}

Questionnaire of Service Utilization and Costs. We chose a narrow definition of the societal perspective in this study, focussing on the most important and common cost categories. ${ }^{21} \mathrm{We}$ considered direct costs, representing the resource utilization caused in the formal health care sector (inpatient services, outpatient services, medications and professional home care), in the informal health care sector (informal unpaid care) and by the intervention itself. Furthermore, we considered indirect costs in the market sector, i.e. productivity losses caused by sick leave and by contacts with health care professionals during working hours. $^{22}$

Unit Costs. Unit costs constituting the foundation of cost calculation are presented in Table 1. Reference year for cost calculation was the 2012. Cost are presented in Euro (€).

Table 1 Unit Costs Considered in the Calculation of Costs

\begin{tabular}{|c|c|c|c|}
\hline Sector & Service/goods & Units & Monetary values (unit costs) \\
\hline Inpatient services & $\begin{array}{l}\text { General hospitals, psychiatric hospitals } \\
\text { and hospitals for rehabilitation }\end{array}$ & Days & Type specific mean rates ${ }^{20}$ \\
\hline Outpatient physician services & GP, psychiatrist, other specialist & Contacts & Type specific mean rates ${ }^{20}$ \\
\hline Outpatient psychotherapist services & Psychotherapist & Contacts & Reimbursement schedule ${ }^{20}$ \\
\hline Medication & Product & Quantity & Official pharmaceutical index (Rote Liste) ${ }^{21}$ \\
\hline \multirow[t]{2}{*}{ Home care } & Professional ambulatory care & Hours & Type specific wage 20 \\
\hline & Informal care & Hours & Type specific wage (replacement cost approach) $)^{20}$ \\
\hline Indirect costs & Productivity losses & Hours & Gross income plus non-wage labour costs ${ }^{22}$ \\
\hline
\end{tabular}


All direct cost categories were valued based on the German opportunity cost based, standardized unit cost catalogue by Bock et al., ${ }^{23}$ except for medication, which was valued based on the Rote Liste, an official German pharmaceutical index. ${ }^{24}$ Indirect costs were calculated based on the human capital approach by using gross income plus non-wage labour costs. ${ }^{25}$

Cost were not discounted as the time horizon of this study was one year.

Intervention Costs. The intervention consisted of structured sessions conducted by the PCP and of clinical monitoring by telephone conducted by the MA. As patients had the opportunity to make use of less or more services, we calculated the intervention costs based on the effective utilization of services.

One interventional session conducted by the physician was valued by $€ 60.66$. Derivation: We chose the opportunity cost approach. A session lasted $27 \mathrm{~min}$ on average. A regular contact with a primary care PCP in Germany has a median duration of $9 \mathrm{~min}^{26}$ This means that in the same time a physician needed to perform the intervention, he could have treated three patients. The societal opportunity costs for an average contact with a PCP are $€ 20.22$. $^{23}$

One clinical monitoring contact by the MA was valued with $€ 8$.13. Derivation: We chose the opportunity cost approach. The gross income plus non-wage compensations of an employee in the German health care system is $€ 32.57$ per hour. One average telephone contact for clinical monitoring lasted $15 \mathrm{~min}$. Therefore, we calculated a fourth of the hourly gross income plus non-wage compensations. ${ }^{25}$

Effects. We performed our analyses based on quality-adjusted life years (QALY).

To calculate QALY, preference-based quality of life and the duration a patient lived in this health state has to be measured.

Preference-based health-related quality of life (HRQL) was measured by the three-level version of the EQ-5D (EQ-5D-3L). ${ }^{18}$ The EQ-5D-3L is a generic HRQL questionnaire. It is composed of five items assessing current problems in the dimensions mobility; self-care; usual activities; pain/discomfort; and anxiety/ depression. ${ }^{18}$ Answers are coded as follows: 1 - no problems; 2 -moderate problems; 3 - extreme problems. The EQ-5D-3L can describe $243^{27}$ health states. For all 243 health states, a utility score (EQ-5D index score) was calculated. In the present study, EQ-5D index scores from the UK were used. ${ }^{28}$ These EQ-5D index scores range from -0.594 (worst health state) to 1 (best health state). The EQ-5D has been validated in populations with anxiety disorders. ${ }^{29}$

QALY were calculated by multiplying the EQ-5D index score with the days the patient lived in this health state. No patients died over the course of the study. We calculated QALY for each 6-month observation period (T0-T1; T1-T2) separately and computed the total 12-month QALY by adding up the periodical values.
Effects were not discounted as the time horizon of this study was 1 year.

\section{Statistical Analysis}

Missing values were imputed on an item level by multiple imputation using chained equations (MICE). ${ }^{30,31}$ The highest share of missing values on the item level was $30 \%$. At baseline, $74 \%$ of participants had no missing values, at T1 63\%, and at $\mathrm{T} 257 \%$ (a comprehensive presentation of missing values per time point and trial arm can be found in Table 5 in the online Appendix). In total, we created 50 datasets based on 93 variables assessed at baseline, $\mathrm{T} 1$, and $\mathrm{T} 2$.

\section{Primary Analysis}

The primary analysis was based on total costs from the societal perspective and QALY. Adjusted differences in mean costs and QALY after 12 months were analysed by means of linear mixed models with bootstrapped standard errors (1000 replications). Variable of interest in these models was the group variable $(0=$ control group; $1=$ intervention group). To account for the clustered structure of the data we included a random effect for primary care practice. The adjustment for baseline differences is recommend in the literature. ${ }^{32,33}$ For this reason, we adjusted the models for variables showing group differences with a $p$ value $\leq$ 0.1 at baseline. This applied to the retirement status, costs (analyses of single cost categories were adjusted for the specific baseline value. The analyses of QALY were adjusted for the total costs at baseline) and health-related quality of life as well as for the presence of joint diseases, depression and somatoform disorders. Additionally, we adjusted the models for age and gender as commonly associated factors of resource utilization and for the presence of gastrointestinal diseases, which showed a rather low $p$ value and might possess a specific influence on the utilization of health care resources of patients with panic disorder. Adjusted cost or effect differences in Table 4 represent the coefficients of the group variable.

In the assessment of cost-effectiveness, we calculated incremental cost-effectiveness ratios (ICER) based on 12-month costs and QALY.

As the ICER is a point estimate and does not consider the uncertainty within the data, we calculated a cost-effectiveness acceptability curve (CEAC) by conducting a series of netbenefit regressions (NBR) using different willingness-to-pay (WTP) margins. ${ }^{34}$ NBR were performed by means of linear mixed models with a random effect for primary care practice and bootstrapped standard errors (1000 replications).

We controlled for the same covariates mentioned in the cost analysis. WTP margins ranged from $€ 0$ per QALY to $€ 150,000$ per QALY.

\section{Supplementary Analyses}

First, we included only health care costs (direct costs) into the cost-effectiveness analyses. Second, we considered 
mental health-specific costs (stays in psychiatric hospital, outpatient contacts with psychiatrists or psychotherapists, utilization of psychopharmacological agents) exclusively. All analyses were conducted with Stata 15.1. (StataCorp, College Station, TX).

\section{RESULTS}

\section{Baseline Characteristics of the Study Population}

The IG contained 230 patients, the CG 189 patients. Table 2 shows the baseline characteristics of IG and CG. Patients in the IG were significantly less frequently retired, had higher costs, lower HRQL values and suffered more frequently from depression and joint diseases.

In total, patients were on average 46 years old; the majority was female and lived in a partnership. More than half of the patients were employed. The mean disease severity was 28 points on the BAI indicating a moderate anxiety disorder. However, $45 \%$ of the patients suffered from severe anxiety (data not shown). HRQL was markedly reduced. The most common comorbidities were cardiovascular diseases (38\% of patients), intestinal diseases $(22 \%)$, and depression (22\%).

\section{Primary Analysis}

Comparison of Costs and Effects. Unadjusted costs and QALY are presented in Table 3. Adjusted differences in costs and QALY after 12 months are presented in Table 4. Total costs in the IG were smaller than in the CG $(-€ 1017$ [SE: $€ 1168])$. Furthermore, there was a tendency to lower costs in the intervention group in most categories, except for intervention costs. No differences in costs except for the intervention costs $(p<0.01)$ were statistically significant.

Statistically significant results in favour of the IG were found for QALY. Patients in the IG gained on average 0.034 additional QALY (SE: $0.015 ; p=0.02$ ) compared to patients in the CG. As the intervention was cost-saving and more effective, the point estimate for the ICER indicated dominance of the intervention.

Probability of Cost-effectiveness. Figure 1 presents the CEAC based on the WTP for one QALY. If WTP was $€ 0 /$ QALY, the probability of cost-effectiveness is $81 \%$. At a WTP of $€ 50,000 / \mathrm{QALY}$, the probability of cost-effectiveness was $96 \%$.] $\rightarrow$

\section{Supplementary Analyses}

Direct Costs. Direct costs accounted for $52 \%$ of total costs in both groups (Table 3). Patients in the IG caused lower adjusted direct costs than patients in the CG (€-679 [SE: €710]). Yet, this difference was not statistically significant.

The CEAC started at a lower level of probability than in the primary analysis (QALY 76\% [Fig. 1]). However, at a WTP of
Table 2 Baseline Characteristics and Group Comparison of the Imputed Sample $(n=50)$

\begin{tabular}{|c|c|c|c|}
\hline Characteristic & $\begin{array}{l}\text { Intervention group } \\
(n=230)\end{array}$ & $\begin{array}{l}\text { Control } \\
\text { group } \\
(n=189)\end{array}$ & $\begin{array}{l}p \\
\text { value }\end{array}$ \\
\hline \multicolumn{4}{|l|}{ Age (years) } \\
\hline Mean (SE) & $46.09(0.93)$ & $46.25(1.07)$ & 0.91 \\
\hline Female: $\%$ & 72.17 & 76.72 & 0.29 \\
\hline Single: $\%$ & 37.39 & 39.68 & 0.63 \\
\hline \multicolumn{4}{|l|}{ Cohibitants } \\
\hline Mean (SE) & $2.52(0.08)$ & $2.33(0.08)$ & \\
\hline \multicolumn{4}{|l|}{ Education (years) } \\
\hline Mean (SE) & $11.20(0.22)$ & $10.87(0.18)$ & 0.25 \\
\hline Employed: \% & 63.26 & 57.51 & 0.26 \\
\hline Retired: \% & 15.11 & 25.40 & 0.01 \\
\hline \multicolumn{4}{|c|}{ Severity of anxiety (BAI) } \\
\hline Mean (SE) & $28.22(0.83)$ & $28.20(0.92)$ & 0.98 \\
\hline \multicolumn{4}{|l|}{ Total costs $(€)$} \\
\hline Mean (SE) & $6021.34(692.34)$ & $\begin{array}{l}4275.66 \\
(471.68)\end{array}$ & 0.04 \\
\hline \multicolumn{4}{|l|}{ EQ-5D Index } \\
\hline Mean (SE) & $0.568(0.019)$ & $\begin{array}{l}0.619 \\
(0.020)\end{array}$ & 0.07 \\
\hline \multicolumn{4}{|l|}{ Comorbidities: \% } \\
\hline Pulmonary diseases & 13.48 & 15.34 & 0.59 \\
\hline Joint diseases & 15.22 & 8.99 & 0.05 \\
\hline Intestinal diseases & 24.35 & 20.11 & 0.30 \\
\hline Cardiovascular & 37.39 & 39.15 & 0.71 \\
\hline \multicolumn{4}{|l|}{ diseases } \\
\hline Depression & 26.09 & 17.99 & 0.05 \\
\hline $\begin{array}{l}\text { Somatic symptom } \\
\text { disorder }\end{array}$ & 11.30 & 6.35 & 0.07 \\
\hline
\end{tabular}

BAI Beck Anxiety Inventory

$€ 50,000$ per QALY, the probability of cost-effectiveness was $95 \%$.

Mental Health-Specific Costs. In both groups, the share of mental health-specific costs in total costs was approximately 18\% (Table 3). After adjustment, the intervention costs were the only cost category with statistically significant differences. However, the IG showed a tendency to lower costs for nearly all services. However, costs for psychopharmaceuticals were

Table 3 Unadjusted Costs and QALY After 12 months

\begin{tabular}{|c|c|c|c|c|}
\hline \multirow[t]{2}{*}{ Category } & \multicolumn{2}{|c|}{$\begin{array}{l}\text { Intervention } \\
\text { group }(n=230)\end{array}$} & \multicolumn{2}{|c|}{$\begin{array}{l}\text { Control group } \\
(n=189)\end{array}$} \\
\hline & Mean & SE & Mean & SE \\
\hline Direct costs & 4369.43 & 514.16 & 4239.46 & 568.69 \\
\hline Inpatient services & 1993.82 & 361.40 & 2208.98 & 449.34 \\
\hline Psychiatric hospital & 653.85 & 264.20 & 837.16 & 324.70 \\
\hline Outpatient services & 854.91 & 74.34 & 776.03 & 62.29 \\
\hline Psychiatrist & 42.29 & 8.47 & 45.24 & 8.87 \\
\hline Psychotherapist & 358.46 & 63.95 & 311.64 & 52.09 \\
\hline Medication & 508.46 & 71.85 & 643.69 & 134.51 \\
\hline Psychopharmaceuticals & 186.94 & 26.09 & 150.17 & 20.80 \\
\hline Professional care & 20.79 & 11.87 & 2.63 & 3.44 \\
\hline Informal care & 728.54 & 207.68 & 608.14 & 180.05 \\
\hline Intervention* & 262.91 & 8.05 & 0 & 0 \\
\hline Indirect costs & 3930.64 & 652.86 & 3637.65 & 567.67 \\
\hline Total costs & 8300.07 & 906.27 & 7877.11 & 958.78 \\
\hline Total mental health costs & 1504.45 & 279.07 & 1344.21 & 339.62 \\
\hline QALY & 0.675 & 0.015 & 0.665 & 0.016 \\
\hline
\end{tabular}

QALY quality-adjusted life year. *Significant difference between intervention group and control group $(p<0.05)$ 
Table 4 Adjusted Differences in Costs and QALY After 12 months

\begin{tabular}{|c|c|c|c|c|c|}
\hline \multirow[t]{2}{*}{ Category } & \multirow[b]{2}{*}{ Mean } & \multirow[b]{2}{*}{ SE } & \multicolumn{2}{|c|}{ 95\% confidence interval } & \multirow[b]{2}{*}{$p$ value } \\
\hline & & & Lower limit & Upper limit & \\
\hline Direct costs & -679.93 & 710.28 & -2072.09 & 712.22 & 0.34 \\
\hline Inpatient services & -618.32 & 581.94 & -1758.94 & 522.29 & 0.29 \\
\hline Psychiatric hospital & -365.06 & 417.85 & -1184.03 & 453.92 & 0.38 \\
\hline Outpatient services & -66.39 & 89.04 & -240.91 & 108.13 & 0.46 \\
\hline Psychiatrist & -12.93 & 11.78 & -36.03 & 11.16 & 0.27 \\
\hline Psychotherapist & -71.41 & 78.47 & -225.21 & 82.39 & 0.36 \\
\hline Medication & -64.41 & 83.30 & -227.69 & 98.86 & 0.44 \\
\hline Psychopharmaceuticals & 22.83 & 26.77 & -29.64 & 75.29 & 0.39 \\
\hline Informal care & -5.28 & 248.46 & -492.25 & 481.70 & 0.98 \\
\hline Intervention* & 254.64 & 10.81 & 233.45 & 275.83 & $<0.01$ \\
\hline Indirect costs & -369.29 & 716.76 & -1774.14 & 1035.56 & 0.60 \\
\hline Total costs & -1017.04 & 1168.01 & -3306.33 & 1272.26 & 0.38 \\
\hline Total mental health costs & -156.93 & 436.08 & -1011.65 & 697.78 & 0.72 \\
\hline QALY* & 0.034 & 0.015 & 0.005 & 0.062 & 0.02 \\
\hline
\end{tabular}

QALY quality-adjusted life year. *Significant difference between intervention group and control group $(p<0.05)$

slightly higher in the IG, yet not statistically significant.

The CEAC showed lower probabilities of cost-effectiveness at a WTP of $€ 0 /$ QALY (64\%; Fig. 1) in comparison to the other CEAC. However, the probability increased reached $98 \%$ at a WTP of $€ 50,000 /$ QALY.

\section{DISCUSSION}

The PARADISE intervention addressed the treatment of panic disorder and aimed at the reduction of symptom severity. The effectiveness of the intervention has already been shown. ${ }^{13}$ Therefore, the aim of our analysis was to provide evidence concerning the cost-effectiveness of the PARADISE intervention.

Our results confirm that the intervention is cost-effective. At a WTP of $€ 50,000 /$ QALY - a frequently adopted margin for cost-effectiveness ${ }^{27}, 35-38$ _the probability of costeffectiveness was at least $95 \%$ in the primary and supplementary analyses. More precisely, we found, on the one hand, no statistically robust evidence that the intervention was cost-saving in total costs or in single cost categories. The main finding that leads us to this conclusion is that there was no statistically significant $(p \leq 0.05)$ cost difference between the groups. Even though there was a probability of $81 \%$ of cost-effectiveness at a margin of $0 € / Q A L Y$, this result should not be misinterpreted. The probability of $81 \%$ implies that there is a $19 \%$ margin of error in assuming that the intervention is cost-saving. This margin of error precludes the assumption that the intervention is cost-saving. However, we observed a significantly higher number of QALY gained by the intervention. Summarizing, under consideration of the significantly better health effects and the high probability of costeffectiveness in the uncertainty analysis, it is justified to conclude that the intervention offers good value for money, even though it does not lead to significant cost savings.

Comparing our results with results from other studies is difficult. Few studies evaluated comparable interventions

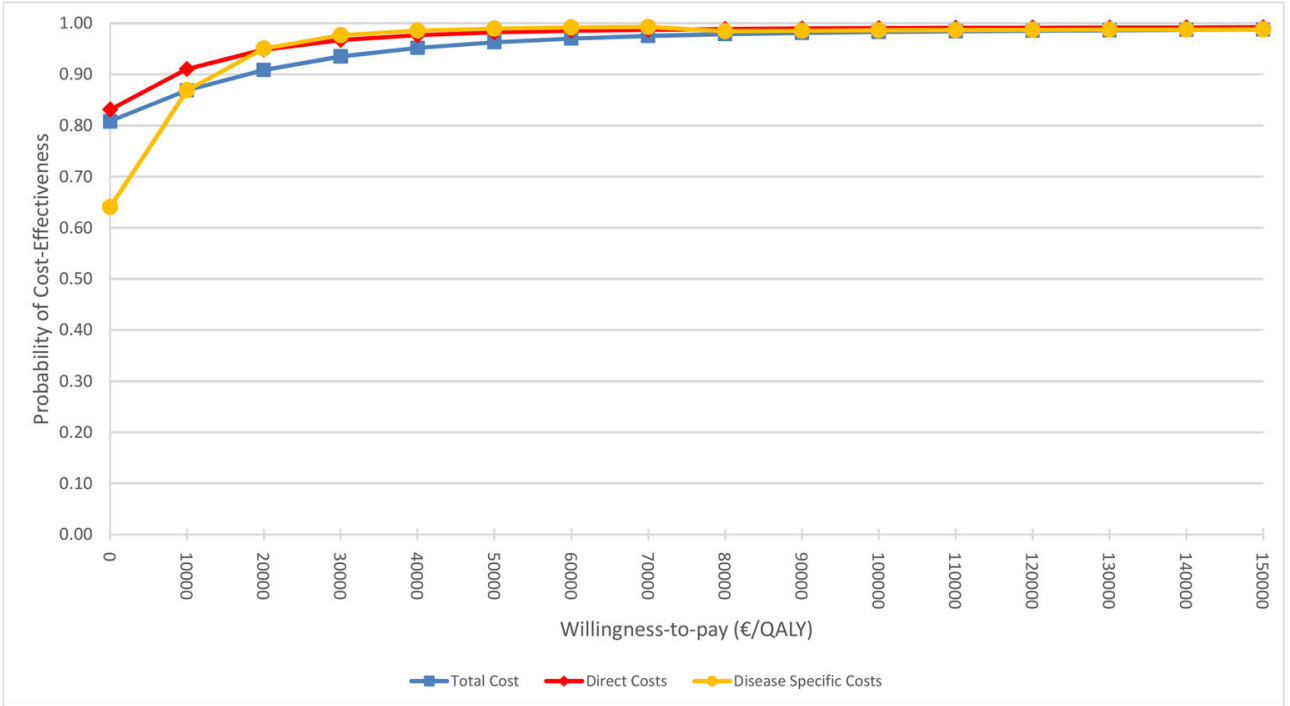

Fig. 1 Cost-effectiveness acceptability curves based on total, direct, and disease-specific cost. 
and in most of these studies, an economic evaluation was not conducted. An exemption is the CBT-based coordinated anxiety learning and management (CALM) treatment model for patients with different anxiety disorders. ${ }^{39,}{ }^{40}$ Non-expert care managers in co-operation with PCP delivered the intervention. The economic evaluation of CALM ${ }^{40}$ identified a tendency to cost-savings in most categories. Yet, there were two categories with higher costs. First, costs for psychopharmacology were slightly higher in the CALM group. This is in line with our findings from PARADISE and might be due to the structured character of both programs where physicians might be more aware of the needs of patients. Second, costs for outpatient physician services were higher in the CALM group, whereas we identified slightly lower costs. Yet, this divergence is simple to explain as in the economic evaluation of CALM there was no specific category for intervention costs. As the intervention was delivered in primary care, interventions costs were part of the costs of outpatient physician services. In our study, intervention costs were a separate cost category.

Looking closer at outpatient costs, we observed significantly increased costs for primary care services in the IG (mean difference: $€ 53.38$ [SE: $€ 19.10] ; p<0.01)$. This increase was independent from the intervention costs. We know from previous cost-ofillness studies that panic disorder not only increases mental health-specific costs but also general health care costs. ${ }^{41} \mathrm{Howev}$ er, costs for general and mental health-specific health care were decreased by the PARADISE intervention. This suggests that for patients with panic disorder an investment in primary care might lead to cost savings in other health care sectors. This relationship should draw greater attention in future research.

The foremost limitation of our randomized study is the different size of the IG $(n=230)$ and the $C G(n=189)$. An explanation for this is that this trial was not blinded. Practice teams recruited participants after the randomization. These circumstances increase the risk of a selection bias. Sociodemographic characteristics like age, gender or education were well balanced between groups. Baseline disease severity was comparable as well. However, there was an imbalance in total costs and health-related quality of life. This indicates that the patients' need for treatment and psychological strain was higher in the IG than in the CG. We assume that practice teams in intervention practices had a high motivation to recruit participants, as they were able to offer patients a disease-specific, innovative treatment. To compensate these imbalances, we adjusted for the corresponding variables. Furthermore, we performed a difference-in-difference analysis of our results to examine if it led to other results (data not shown). The results were comparable. Considering this, we conclude that our results are robust. A further limitation is in the narrow interpretation of the social perspective. Due to the nonconsideration of e.g. voluntary work or patient time for reasons of necessity to keep the responder burden low, our results might be biased. However, based on a review by Drost et al., our interpretation of the societal perspective is in line with the major part of the literature and hence our results can be assumed to be suitable for comparisons. ${ }^{21}$ An additional limitation could arise from the imputation of missing values. MICE is based on the assumption of missing at random (MAR). MAR implies that missing values do not depend on the unobserved but only on the observed data. As unobserved data are unknown, this assumption cannot be tested. ${ }^{31,42}$ However, considering a high number of observed data can reduce the risk of bias. ${ }^{31}$

\section{CONCLUSION}

The PARADISE intervention-a practice team-supported exposure training for panic disorder and agoraphobia in primary care-is likely to be cost effective, delivering high value for money.

Corresponding Author: Christian Brettschneider, $\mathrm{PhD}$; Department of Health Economics and Health Services Research, Hamburg Center for Health Economics University Medical Center Hamburg-Eppendorf, Hamburg, Germany (e-mail: c.brettschneider@uke.de).

Funding Information Open Access funding provided by Projekt DEAL. This study was supported by a grant from the German Federal Ministry of Education and Research (Grant no.: O1GY1146). The sponsor had no role in the design and conduct of the study, collection, management, analysis, and interpretation of the data, nor in preparation, review, and approval of the manuscript and in the decision to submit.

Data Availability The datasets analysed during the current study are available from the corresponding author on reasonable request.

\section{Compliance with Ethical Standards:}

Ethics: The study protocol was approved by the ethics committee of the Friedrich-Schiller-University at the Medical Faculty in Jena, Germany (reference 3484-06/12) and has been published. ${ }^{43}$ All participants gave their informed consent before inclusion in the study.

Conflict of Interest: The authors declare that they do not have a conflict of interest.

Open Access This article is licensed under a Creative Commons Attribution 4.0 International License, which permits use, sharing, adaptation, distribution and reproduction in any medium or format, as long as you give appropriate credit to the original author(s) and the source, provide a link to the Creative Commons licence, and indicate if changes were made. The images or other third party material in this article are included in the article's Creative Commons licence, unless indicated otherwise in a credit line to the material. If material is not included in the article's Creative Commons licence and your intended use is not permitted by statutory regulation or exceeds the permitted use, you will need to obtain permission directly from the copyright holder. To view a copy of this licence, visit http:// creativecommons.org/licenses/by/4.0/.

\section{REFERENCES}

1. American Psychiatric Association. Diagnostic and Statistical Manual of Mental Disorders, Fifth Edition (DSM-5). Arlington, VA: American Psychiatric Association; 2013.

2. Kessler RC, Chiu WT, Demler O, Merikangas KR, Walters EE. Prevalence, severity, and comorbidity of 12-month DSM-IV disorders in the National Comorbidity Survey Replication. Arch Gen Psychiatry. 2005;62(6):61727.

3. Jacobi F, Höfler M, Siegert J, Mack S, Gerschler A, Scholl L, et al. Twelvemonth prevalence, comorbidity and correlates of mental disorders in 
Germany: the Mental Health Module of the German Health Interview and Examination Survey for Adults (DEGS1-MH). Int J Methods Psychiatr Res. 2014;23(3):304-19.

4. Saarni SI, Suvisaari J, Sintonen H, Pirkola S, Koskinen S, Aromaa A, et al. Impact of psychiatric disorders on health-related quality of life: general population survey. Br J Psychiatry. 2007;190(4):326-32.

5. Beard C, Weisberg RB, Keller MB. Health-related Quality of Life across the anxiety disorders: findings from a sample of primary care patients. $J$ Anxiety Disord. 2010;24(6):559-64.

6. Konnopka A, Leichsenring F, Leibing E, König H-H. Cost-of-illness studies and cost-effectiveness analyses in anxiety disorders: a systematic review. J Affect Disord. 2009;114(1):14-31.

7. Woud ML, Zhang XC, Becker E, McNally RJ, Margraf J. Don't panic: Interpretation bias is predictive of new onsets of panic disorder. J Anxiety Disord. 2014;28:83-7.

8. Rudaz M, Craske M, Becker E, Margraf J. Health anxiety and fear of fear in panic disorder, agoraphobia, and social phobia: A prospective longitudinal study. Depress Anxiety. 2010;27:404-11.

9. Wang PS, Lane M, Olfson M, Pincus HA, Wells KB, Kessler RC. Twelvemonth use of mental health services in the United States: results from the National Comorbidity Survey Replication. Arch Gen Psych. 2005;62(5):629-40.

10. Young AS, Klap R, Sherbourne CD, Wells KB. The quality of care for depressive and anxiety disorders in the United States. Arch Gen Psychiatry. 2001;58:55-61.

11. Muntingh $\mathrm{AD}$, van der Feltz-Cornelis CM, van Marwijk HW, Spinhoven P, van Balkom AJL. Collaborative care for anxiety disorders in primary care: a systematic review and meta-analysis. BMC Fam Pract. 2016;17:62.

12. German Chamber of Psychotherapists. BPtK Study: Waiting Times for outpatient psychotherapeutic services. German Chamber of Psychotherapists, Berlin. 2011. http://www.npce.eu/mediapool/113/1137650/data/NPCI_Info_waitinglists_EN.pdf. Accessed December 132019.

13. Gensichen J, Hiller TS, Breitbart J, Brettschneider C, Teismann T, Schumacher U, et al. Patients with Panic Disorder in Primary Care: Effects of Practice-Team-Supported Exercises. A Cluster Randomized Clinical Trial. Dtsch Arztebl Int. 2019;(accepted).

14. Norman SB, Campbell-Sills L, Hitchcock CA, Sullivan S, Rochlin A, Wilkins KC, et al. Psychometrics of a brief measure of anxiety to detect severity and impairment: the Overall Anxiety Severity and Impairment Scale (OASIS). J Psychiatr Res. 2011;45(2):262-8.

15. Löwe B, Gräfe K, Zipfel S, Spitzer RL, Herrmann-Lingen C, Witte S, et al. Detecting panic disorder in medical and psychosomatic outpatients: comparative validation of the Hospital Anxiety and Depression Scale, the Patient Health Questionnaire, a screening question, and physicians' diagnosis. J Psychosom Res. 2003;55(6):515-9.

16. Spitzer RL, Kroenke K, Williams JB. Validation and utility of a self-report version of PRIME-MD: the PHQ primary care study. Primary Care Evaluation of Mental Disorders. Patient Health Questionnaire. JAMA. 1999;282(18): 1737-44.

17. Federal Ministry of Health, Federal Ministry of Research and Education. Verordnung über die Berufsausbildung zum Medizinischen Fachangestellten/zur Medizinischen Fachangestellten [Regulation concerning the vocational training for medical assistants]. Bundesgesetzblatt. 2006; Teil I:Nr. 22.

18. Euro@ol Group. Euroßol-a new facility for the measurement of healthrelated quality of life. Health Policy. 1990;16(3): 199-208.

19. Beck AT, Steer RA. Beck Anxiety Inventory Manual. San Antonio: Harcourt Brace and Company; 1993.

20. Margraf J, Ehlers A. Beck Angst-lnventar (BAI) - Manual [Beck Anxiety Inventory (BAI) - manual]. Frankfurt am Main: Pearson Assessment \& Information $\mathrm{GmbH} ; 2007$.

21. Drost RMWA, van der Putten IM, Ruwaard D, Evers SMAA, Paulus ATG. Conceptualizations of the societal perspective within economic evaluations: a systematic review. Int $\mathrm{J}$ Technol Assess Health Care. 2017;33(2):251-60.

22. Sanders GD, Neumann PJ, Basu A, Brock DW, Feeny D, Krahn M, et al Recommendations for Conduct, Methodological Practices, and Reporting of Cost-effectiveness Analyses: Second Panel on Cost-Effectiveness in Health and Medicine. JAMA. 2016;316(10):1093-103.

23. Bock JO, Brettschneider C, Seidl H, Bowles D, Holle R, Greiner W, et al [Calculation of standardised unit costs from a societal perspective for health economic evaluation]. Gesundheitswesen. 2015;77(1):53-61.

24. Rote Liste Service GmbH. Rote Liste 2012. Frankfurt/Main: Rote Liste Service GmbH; 2012.

25. German Federal Statistical Office. Verdienste und Arbeitskosten. Wiesbaded: German Federal Statistical Office; 2012.
26. Koch K, Miksch A, Schürmann C, Joos S, Sawicki PT. The German Health Care System in International Comparison: The Primary Care Physicians' Perspective. Dtsch Arztebl Int. 2011;108(15):255-61.

27. Pandya A, Sy S, Cho S, Weinstein MC, Gaziano TA. Cost-effectiveness of 10-Year Risk Thresholds for Initiation of Statin Therapy for Primary Prevention of Cardiovascular Disease. JAMA. 2015;314(2):142-50.

28. Dolan P. Modeling valuations for Euroßol health states. Med Care. 1997;35(11): 1095-108.

29. König HH, Born A, Günther O, Matschinger H, Heinrich S, Riedel-Heller SG, et al. Validity and responsiveness of the EQ-5D in assessing and valuing health status in patients with anxiety disorders. Health Qual Life Outcomes. 2010;8:47.

30. Azur MJ, Stuart EA, Frangakis C, Leaf PJ. Multiple imputation by chained equations: what is it and how does it work? Int $\mathrm{J}$ Methods Psychiatr Res. 2011;20:40-9.

31. White IR, Royston P, Wood AM. Multiple imputation using chained equations: Issues and guidance for practice. Stat Med. 2011;30:37-399.

32. Ramsey SD, Willke RJ, Glick H, Reed SD, Augustovski F, Jonsson B, et al. Cost-Effectiveness Analysis Alongside Clinical Trials II-An ISPOR Good Research Practices Task Force Report. Value Health. 2015;18(2):161-72.

33. van Asselt ADI, van Mastrigt GAPG, Dirksen CD, Arntz A, Severens JL. How to Deal with Cost Differences at Baseline. Pharmacoeconomics. 2009;27(6):519-28.

34. Briggs AH, O'Brien BJ, Blackhouse G. Thinking outside the box: recent advances in the analysis and presentation of uncertainty in costeffectiveness studies. Annu Rev Public Health. 2002;23:377-401.

35. Chahal HS, Marseille EA, Tice JA, Pearson SD, Ollendorf DA, Fox RK, et al. Cost-effectiveness of Early Treatment of Hepatitis C Virus Genotype 1 by Stage of Liver Fibrosis in a US Treatment-Naive Population. JAMA Intern Med. 2016;176(1):65-73.

36. Forster A, Dickerson J, Young J, Patel A, Kalra L, Nixon J, et al. A structured training programme for caregivers of inpatients after stroke (TRACS): a cluster randomised controlled trial and cost-effectiveness analysis. Lancet. 2013;382(9910):2069-76.

37. Moran AE, Odden MC, Thanataveerat A, Tzong KY, Rasmussen PW, Guzman D, et al. Cost-effectiveness of hypertension therapy according to 2014 guidelines. N Engl J Med. 2015;372(5):447-55.

38. Gyrd-Hansen D, Olsen KR, Bollweg K, Kronborg C, Ebinger M, Audebert HJ. Cost-effectiveness estimate of prehospital thrombolysis: results of the PHANTOM-S study. Neurology. 2015;84(11):1090-7.

39. Roy-Byrne P, Craske MG, Sullivan G, Rose RD, Edlund MJ, Lang AJ, et al. Delivery of evidence-based treatment for multiple anxiety disorders in primary care: a randomized controlled trial. JAMA. 2010;303(19):1921-8.

40. Joesch JM, Sherbourne CD, Sullivan G, Stein MB, Craske MG, RoyByrne P. Incremental benefits and cost of coordinated anxiety learning and management for anxiety treatment in primary care. Psychol Med. 2012;42(9): 1937-48.

41. Batelaan N, Smit F, de Graaf R, van Balkom A, Vollebergh W, Beekman A. Economic costs of full-blown and subthreshold panic disorder. J Affect Disord. 2007; 104:127-36.

42. van Buuren S. Flexible Imputation of Missing data. Boca Raton FL: CRC Press, Taylor \& Francis Group; 2012.

43. Gensichen J, Hiller TS, Breitbart J, Teismann T, Brettschneider C, Schumacher U, et al. Evaluation of a practice team-supported exposure training for patients with panic disorder with or without agoraphobia in primary care - study protocol of a cluster randomised controlled superiority trial. Trials. 2014;15:112.

Publisher's Note Springer Nature remains neutral with regard to jurisdictional claims in published maps and institutional affiliations. 